\title{
Observações sobre produção, Gênio, gosto e apreciação na Crítica do Juízo
}

\section{Remarks about production, Genius, taste and appreciation on the Critique of Judgment}

\author{
Carlos Henrique dos Santos Fernandes \\ Graduando, Curso de Bacharelado em Filosofia, Universidade Federal de São Carlos - UFSCar, \\ São Carlos, SP, Brasil.
}

Resumo: O objetivo deste artigo é apresentar três relações entre produção, Gênio, gosto e apreciação, analisando, sob o eixo do Juízo-de-reflexão estético puro, os \$§43-54 e §59, da Crítica do Juízo.

Palavras-chave: produção, gênio, gosto, apreciação, imaginação.

\begin{abstract}
The objective of this subject is to present three relations between production, Genius, taste, and appreciation, analyzing, by the axis of aesthetic pure reflective judgments, the $\$ \S 43-54$ and $\S 59$ of the Critique of Judgment.
\end{abstract}

Keywords: production, genius, taste, appreciation, imagination. 


\section{O juízo determinante e o juízo reflexionante}

Na Introdução à Crítica do Juízo ${ }^{1}$, após discutir: a) a divisão da filosofia em teórica e prática, b) em natureza e liberdade e c) a posição da terceira Crítica como elo entre as duas partes da filosofia, Kant apresenta o "Juízo como uma faculdade legisladora $a$ priori". Segundo o filósofo, à medida que nos é dado o universal, "a regra, o princípio, a lei", ao incluirmos, por intermédio do Juízo, o particular, este será determinante; em contrapartida, dado o particular, ao encontrarmos, também mediante o Juízo, o universal, tal juízo então será reflexionante (KANT, 1995, p. 106).

No Juízo determinante "a lei lhe é designada a priori", o que significa que ele "não necessita pensar por si mesmo" em uma lei que inclua o particular no universal. Já o Juízo reflexionante precisa dessa lei como princípio, o qual, sem tomá-lo de "empréstimo à experiência", funda "a unidade de todos os princípios empíricos". Caso contrário, se o Juízo reflexionante buscasse na experiência o seu princípio, ele estaria subordinado a outros princípios também empíricos. Portanto, a solução do Juízo reflexionante é dar-se "a si mesmo" tal princípio como lei (Ibidem, p. 106-107).

Ao considerar que o princípio do Juízo reflexionante é o que "[...] nelas [nas leis empíricas particulares] foi deixado indeterminado [...]" (Ibidem, p. 107), o filósofo recorre a uma comparação:

[...] as leis empíricas particulares [...] têm de ser consideradas segundo uma unidade tal como se um entendimento (ainda que não o nosso) as tivesse dado para bem de nossas faculdades de conhecimento, a fim de tornar possível um sistema de experiência segundo leis particulares da natureza.

Nesse "como se" vemos que não é que "um tal entendimento tivesse de ser efetivamente admitido" - senão não se trataria de um Juízo reflexionante e, sim, determinante -, mas, antes, trata-se de notar que tal linguagem, ao elaborar símiles ou metáforas, desvela à letra o espírito e o comunica com maior e melhor exatidão. Em outras palavras, à linguagem kantiana é exigido um símile, um paradoxo, para que seja clara a exposição do princípio que fundamenta o Juízo reflexionante: é "como se" a unidade das leis empíricas particulares fosse dada pelo entendimento que um sistema da experiência, em concordância com leis empíricas particulares, torna-se possível.

Não obstante, como atentamente observa Lebrun, em Sobre Kant: "Essa ordem, em si mesma, é contingente [...] poderia se dar de outra maneira [...]" (LEBRUN, 2010, p. 100). Isto significa que, no Juízo reflexionante, só há "entendimento" por analogia, e essa concordância ou "organização da natureza" deve ser "julgada contingente" (KANT, 1995, p. 115). Analogia: será assim que "falaremos, então, da natureza por analogia com a arte" (LEBRUN, 2010, p. 100).

Nesse sentido, para sintetizar melhor a relação entre o simbólico e o lógico, apresentada por Kant, na "Segunda Introdução" da terceira crítica, podemos nos servir do que Pimenta, em Kant e a estrutura orgânica da razão, observa com precisão ao dizer que: "a clareza estética vem auxiliar a reforçar a clareza lógica que é a alma da exposição" (PIMENTA, 2008, p. 133). Isto é, o simbolismo, símile ou metáfora, pode tornar-se correspondente, em certa medida, do esquematismo kantiano, porque, ao simbolizar, o simbolismo desnuda a letra revelando o "espírito lógico" dela - apesar do esquematismo ser a "base" da linguagem. Tentemos, por isso, partindo do início da terceira crítica, expor esta "clareza estética".

\footnotetext{
${ }^{1}$ Trata-se da introdução definitiva da terceira crítica, também conhecida como "Segunda Introdução", traduzida por Carlos A. Marques Novaes, Herbert Bornebusch, Márcio Suzuki, Marcos S. Nobre, Moacyr A. Novaes Filho, Ricardo R. Terra e Ruth P. Duarte Lanna. Publicada, em 1995, em Duas introduções à Crítica do Juízo, sob a organização de Ricardo R. Terra, a "Segunda Introdução" aparece como apêndice à Primeira Introdução à Crítica do Juizo, em tradução aperfeiçoada por Rubens Rodrigues Torres Filho, pouco mais de vinte anos depois da primeira versão publicada na coleção "Os Pensadores", em 1974, pelo mesmo tradutor.
} 


\section{O Juízo-de-gosto}

Antes mesmo de começar o §1. O Juízo-de-gosto é estético, da Crítica do Juízo, Kant é cuidadoso em oferecer, na nota de rodapé, a definição de gosto como "a faculdade do julgamento do belo" (KANT, 1974, p. 303). É preciso tomar esta definição "por fundamento", de maneira que todo leitor da terceira crítica não se antecipe em uma generalização que admita o gosto (sobre o belo) como, também, aquilo que é dado pela mera sensação (sobre o agradável) e/ou dado pela moral (sobre o bom).

O Juízo-de-gosto sobre o belo dá-se quando a representação é referida mediante a imaginação, "talvez vinculada com o entendimento", ao sentimento de prazer do sujeito judicante; e, visto que o seu "[...] fundamento-de-determinação não pode ser outro do que subjetivo [...]" (Ibidem, p. 303), este Juízo, por isso mesmo, é estético.

Além de estético, o Juízo-de-gosto é também "sem nenhum interesse". Ele exige despreocupação e indiferença: o sujeito que julga tem de despreocupar-se da "existência da coisa" e ser "inteiramente indiferente" em seu Juízo. Este será um Juízo-de-gosto puro se a satisfação que tenho, ao contemplar algo, ao intuí-lo ou julgá-lo por reflexão, partir de e voltar $a$ "mim mesmo" (Ibidem, p. 304) - aliás, essa é a conditio sine qua non podemos dizê-lo belo.

Às qualidades antes citadas, somamos ao Juízo-de-gosto também a qualidade de universalidade-subjetiva. Nos $\$ \S 6$ e 8, mormente, encontramos a exposição do fundamento da universalidade-subjetiva do Juízo de gosto: ele é universal porque a condição de sua satisfação não é privada mas pressuposta a "todo outro", ou seja, é um sentimento e não uma sensação (uma ideia e não um conceito) de "validade para todos" (Ibidem, p. 309).

Para Kant, como afirma Nascimento, em Intersubjetividade e senso comum em Kant: "sem a pressuposição de uma comunicabilidade ou senso comum, não existe gosto" - e continua - "não há consciência do acordo entre imaginação e entendimento" (NASCIMENTO, 2008, p. 120). Mais adiante discutiremos sobre o aspecto desse acordo entre as duas faculdades. Vale, no momento, enfatizar a questão da comunicabilidade, pois, ao julgar algo belo, pressuponho que todos hão de concordar comigo, já que, conforme a primorosa e paradoxal expressão de Lebrun, em Os paradoxos da intersubjetividade, é "no momento em que mais pareço curvar-me sobre minha singularidade, [que] eu me sinto universal" (LEBRUN, 2002b, p. 489).

Contudo, essa universalidade é, ao mesmo tempo, também, subjetiva, posto que ela "tem de ser de espécie particular", uma vez que o "predicado da beleza" não se "estende" inteiramente à lógica ou ao conceito do objeto, e sim aos judicantes, isto é, àqueles que julgam algo belo (KANT, 1974, p. 312). Acreditamos que uma breve exposição da distinção que Kant opera entre arte em geral e bela-arte possa esclarecer melhor, tanto o Juízo-de-gosto, quanto a sua comunicabilidade.

\section{A arte como se fosse natureza: a finalidade sem fim}

Em O Gênio e a Linguagem do Imaginário, é pelo modo que Lebrun denomina de "divisões sucessivas" (LEBRUN, 2002c, p. 529), que Kant, opondo a arte: à natureza, à ciência e ao artesanato, nos $\S \S 43-46$, atinge a "condição suficiente" das belas-artes em relação à "arte em geral". O que Lebrun está tentando nos dizer com isso é que a "essência" das belas-artes é atingida quando, em primeiro lugar, o autor da terceira crítica separa a arte da natureza e, em segundo, mostra que a passagem da arte à natureza se dá por intermédio da bela-arte, a qual é a "única reconciliação possível entre esses opostos" (Idem, 2002c, p. 529-530).

Segundo a exposição lógica (esquemática), a oposição entre arte e natureza torna-se necessária para que se distinga a produção humana (operação permitida pela 
liberdade e pelo raciocínio) da produção animal (operação instintiva), de maneira que a primeira não seja fadada ou atribuída ao acaso. Ora, é com o respaldo da exposição estética (simbólica) que Kant (1974, p. 337), no §43, "reforça" a clareza da lógica desse rompimento entre as produções animal e humana:

[...] se bem que gostem de denominar o produto das abelhas (os favos da cera regularmente construídos) uma obra de arte, isso ocorre, no entanto, somente em virtude da analogia com esta última [a obra de arte].

É por que pensamos uma finalidade, na produção animal, que a consideramos "como se fosse" arte, pois esta é fundada na reflexão de um produtor, de um artista, à medida que as abelhas tampouco pensam no "efeito" enquanto "obra": elas sequer pensam; apenas produzem instintivamente, ao passo que os homens, para que produzam obras de arte, precisam de técnica, ou seja, precisam tanto de regras teóricas (raciocínio), quanto de capacidade manual para produzi-las.

Mas a cisão estabelecida entre arte e natureza, que assegura o lugar das obras de arte enquanto belas-artes, sem relegá-las ao hall dos meros produtos artesanais, mecânicos, remunerados, dando-lhas seu devido valor, de algum modo não é absoluta para Kant. Pois, podemos dizer que o filósofo averigua uma "exceção" à cisão entre arte e natureza, na qual ambas então terminam por se reconciliar; como se houvesse uma passagem de uma a outra, ao invés de um rompimento abrupto. Essa transposição é observada na bela-arte na medida em que ela então "parece ser natureza".

O §45, poder-se-á afirmar, é o bojo da exposição desse paradoxo que enseja tornar natural o artificial, e mitiga a cisão que, à primeira vista, parecia absoluta e radical. Nesse parágrafo é possível constatar que a finalidade da bela-arte tem de parecer tão "livre de toda coação de regras", tão sem intenção ou pretensão explícita de possuir um fim, que ela aparece "como se fosse um produto da mera natureza". De modo oximoro, podemos dizer finalidade sem fim: a arte que aparece como natureza, embora possua "concordância com regras", secreta todo "vestígio de que a regra esteve diante dos olhos do artista", como se sua mente estivesse em um "livre jogo das faculdades" (Ibidem, 1974, p. 340), em sua criação, e que, por conseguinte, comunica.

\section{As relações entre produção, Gênio, gosto e apreciação}

Com efeito, a temática acerca da produção artística possui um correlato imediato e indispensável em seu interior: o Gênio. No §46, Kant estabelece que a produção das belas-artes está única e exclusivamente sob tutela do Gênio: "[...] belas-artes têm de ser necessariamente consideradas como artes do gênio [...]" (KANT, 1974, p. 340).

O Gênio é dotado de certo talento para a arte, isto é, "aquilo para o qual não se pode dar nenhuma regra determinada" (Ibidem, 1974, p. 340); talento que nasce e morre com ele até que, de acordo com o $§ 47$, "a natureza alguma vez dote novamente do mesmo modo um outro" (Ibidem, 1974, p. 342), sendo sempre original em suas produções: tanto que nem ele mesmo é capaz de reproduzi-las. Suas obras, por isso, são sempre exemplares, paradigmas para outro Gênio, "como justa-medida ou regra do julgamento" (Ibidem, 1974, p. 340).

Para Kant, o processo de produção do artista é de tamanha estranheza que nem ele mesmo, o Gênio, é capaz de descrevê-lo:

[...] nenhum Homero, porém, ou Wieland, pode indicar como suas ideias, ricas em fantasia e no entanto, ao mesmo tempo, repletas de pensamento, surgem e se reúnem em sua cabeça [...] (Ibidem, p. 341). 
Sua linguagem pode soar-nos estranha, que seja, "[...] mas que ela permaneça suficientemente inteligível para que possamos apreciá-la deste modo [...]" (LEBRUN, 2002c, p. 556).

Segundo o $\$ 49$, é o seu espírito que o Gênio põe na obra que produz (espírito que serve de "escola" para outros espíritos, "instrução metódica de regras") e que lhe permite imitar sem "macaqueação". Sem espírito, toda imitação não passa de um pastiche, de uma imitação ruim que se nutre, não de "sentimento", mas tão somente de "princípios determinados" (KANT, 1974, p. 349). Entretanto, é preciso observar que tais "regras determinadas" são imprescindíveis à produção das belas-artes, porque ao Gênio é requerido gosto.

No §50, Kant (Ibidem, p. 350) considera o gosto como "a disciplina (ou cultivo) do gênio, [que] corta-lhe muito as asas", mas que, no entanto, dá-lhe uma "direção"; pois, caso contrário - como já afirmara Kant, no §47, mediante uma imagem acreditar-se-ia "que se desfila melhor em um cavalo furioso do que em um cavalo domado" (Ibidem, pp. 342-343). Em outros termos, sem o gosto restaria apenas uma arte genial, "rica em espírito", livre e sem lei, logo, mera "insensatez".

Se, por um lado, a produção corresponde ao Gênio e são portanto correlatos, esta afinidade não impede que o Gênio seja correspondente também do gosto. No primeiro caso, como vimos, a elaboração da bela-arte é exclusiva do Gênio; já no segundo caso, uma relação de dependência, de condição de existência entre Gênio e gosto para que surja a bela-arte. Vejamos melhor esse último caso.

Gênio com gosto é aquele que diz o indizível, torna visível o invisível, faz ouvir o inaudível, transforma o intocável em algo tangível e o inodoro em algo olfativo, comunica-o com clareza, quer "pela linguagem, quer pela pintura ou pela plástica", pois dispõe adequada e harmoniosamente suas faculdades, quais sejam, imaginação e entendimento. Disposição que, todavia, caso entre em conflito no sujeito, tem de operar sempre a favor do entendimento e em detrimento "à liberdade e à riqueza da imaginação" (Ibidem, p. 350).

Em sentido inverso, podemos pensar no Gênio sem gosto. Sem polimento, ele se assemelha a um desvairado que não distingue realidade de fantasia, confuso e desgovernado, cuja imaginação é repleta de imagens aleatórias e sem limites, sem rédeas ou guia; sua arte não se comunicaria, uma vez que faltariam "clareza e ordem" às suas ideias; no limite, ele careceria de entendimento e tornar-se-ia um louco.

De fato, a arte, ou melhor, a bela-arte, para o Gênio, "em alguma parte se detém, na medida em que the é posto um limite, além do qual ela não pode ir" para que seja compreendida pelos seus apreciadores (Ibidem, p. 342).

Não obstante, como revela o início do $\$ 49$, há produções que possuem gosto, mas não são geniais.

Uma história é exata e ordenada, mas sem espírito. Um discurso solene é bem fundado, e ao mesmo tempo bem ornamentado, mas sem espírito [...] mesmo de uma moça costuma-se dizer, ela é bonita, expansiva e amável, mas sem espírito (Ibidem, p. 345).

Desse modo, o Gênio depende do gosto para produzir a bela-arte, assim como o gosto só opera com o espírito do Gênio e, ambos, em favor das belas-artes. O Juízo-de-gosto torna a imaginação "adequada ao entendimento" independentemente da abundância e originalidade das ideias - ou de qualquer outro atributo do Gênio. O gosto disciplina, educa, regra, aperfeiçoa, repara, pule ${ }^{2}$ ao mesmo tempo em que dirige o pensamento do artista, a fim de que sua arte dure, eternize-se, seja universal e comunique, ou seja, produza a bela-arte (Ibidem, p. 350).

\footnotetext{
${ }^{2}$ Forma do verbo polir na terceira pessoa do singular do presente do indicativo.
} 
Ademais destas distintas relações apresentadas entre produção e Gênio, Gênio e gosto, cujo objetivo deste artigo era propô-las de modo que evidenciasse o caráter paradoxal da linguagem kantiana, podemos cogitar, ainda, outra relação igualmente emblemática, agora entre gosto e apreciação.

Aqueles que não são dotados, como os Gênios, para a produção ou fabricação - que, neste caso, são muitos -, podem, no entanto, apreciar as belas-artes. Ao contemplá-las, pomos em atividade reflexiva o gosto, enquanto capacidade de julgar o belo, e é o caráter de "concordâncias contingentes"3 das belas-artes, cuja significação é múltipla, que nossa visão é levada para "um campo inabarcável de representações aparentadas". Como exemplifica Kant:

Assim a águia de Júpiter, com o relâmpago nas garras, é um atributo do poderoso rei dos céus, e o pavão o é da soberba rainha dos céus. Não representam, como atributos lógicos, aquilo que está contido em nossos conceitos da sublimidade e majestade da criação, mas algo outro, que dá ensejo à imaginação de estender-se sobre uma multidão de representações aparentadas, que dão mais a pensar do que pode exprimir-se em um conceito determinado por palavras [...] (Ibidem, p. 346).

As belas-artes são apresentadas, no §51, mediante a analogia com o falar humano, com o discurso. Essa exposição estética das belas-artes divide-se em três modos: "as elocutivas, as figurativas e a arte do jogo das sensações", o que equivale no discurso: "a palavra, o gesto e o som" (Ibidem, p. 350). Em síntese, parte das artes puramente reflexíveis (a eloquência e a poesia), passa pelas artes plásticas e pela pintura, encerrando-se nas artes agradáveis, mais sensoriais, como a música e as cores.

Contudo, essa divisão pode ser relativizada e, por isso, falar em níveis qualitativos das belas-artes opaca a relação delas entre si. Assim como em um discurso em que palavras, gestos e sons são articulados pelo orador para chamar a atenção dos seus ouvintes - ora por meio de gesticulações rápidas, ora por uma elevação do tom da voz ou acentuação de uma palavra -, nas belas-artes também é possível observar estes fenômenos, como escreve Kant no início do §52:

A eloquência pode estar vinculada com uma exposição pictórica, tanto de seus sujeitos, quanto de objetos, em uma peça teatral; a poesia com a música, no canto [...] (Ibidem, 1974, p. 354).

E fica, por certo, difícil (talvez impróprio) "medir" o valor de cada uma dessas artes.

Por fim, gostaríamos de vincular brevemente os parágrafos analisados até aqui com o §59. Da beleza como símbolo da moralidade. Neste parágrafo vemos que é também somente por analogia que justapomos os juízos estéticos aos juízos morais:

Chamamos edifícios ou árvores de majestosos ou suntuosos, ou campos, de risonhos e alegres, mesmo cores são chamadas de inocentes, modestas, ternas, porque elas suscitam sensações que contêm algo analógico à consciência de um estado de ânimo produzido por juízos morais (KANT, 2005, p. 198-199).

Aqui, cabe relembrarmos, mais uma vez, o tema do "senso comum" kantiano. Enquanto no Juízo estético o "senso comum" é inconscientemente explícito, no Juízo moral, como evidencia Lebrun, sua explicitação é "consciente", ou seja, leva em consideração o pensamento coletivo, social e:

Assim, a filosofia prática abre-se um caminho através da 'estética do juízo reflexionante', e se entrevê a passagem do teórico ao prático que a faculdade de Julgar tem como missão assegurar (LEBRUN, 2002d, p. 592).

\footnotetext{
${ }^{3}$ Lebrun, em A Razão Prática na Crítica do Juízo, revela a importância desta expressão, diz ele: "Concordância (Zasammemnstimmung) é uma das palavras essenciais da Crítica do Juízo. Enquanto a primeira Crítica tornara inteligível o acordo entre a forma da natureza e nosso entendimento, a faculdade de julgar nos coloca em presença de concordâncias contingentes, e, não obstante, maravilhosas demais para serem atribuídas ao acaso." (LEBRUN, 2010, p. 110).
} 


\section{Breve nota sobre a imaginação}

Ao analisarmos alguns parágrafos da Crítica do Juízo, com a finalidade de expor algumas relações entre gosto, Gênio, produção e apreciação, deparamo-nos com um emaranhado de paradoxos: universalidade-subjetiva, finalidade sem fim, a bela-arte como se fosse um discurso, os juízos estéticos como se fossem os juízos morais etc. São enormes as dificuldades dessas, se assim podemos dizer, determinações-indeterminadas.

Com efeito, quanto às três relações que apresentamos, quais sejam, produção e Gênio, Gênio e gosto, e, por fim, Gosto e Apreciação, podemos concluir que: a) apenas o Gênio produz a bela-arte, a qual, mesmo para ele, é indecifrável e, em certo sentido, misteriosa; b) o Gênio sem gosto resulta num artista desordenado, obscuro e até mesmo louco, motivo pelo qual somente a sua relação com o gosto lhe permite unir seu espírito à regra e à educação na produção da bela-arte, e c) os indivíduos que não são dotados de talento e espírito podem, por outro lado, cultivar e pôr em atividade reflexiva o gosto, apreciando a bela-arte e julgando o belo.

Se, por um lado, acreditamos que essas relações (que superficialmente analisamos aqui e que não esgotam o campo de tantas outras relações possíveis) evidenciam a condição paradoxal da linguagem estética da Crítica do Juízo, por outro lado, ainda mais interessante, elas levantam o problema da relação entre as faculdades de imaginar e de conhecer.

Por essa razão, para finalizar nosso estudo, gostaríamos de introduzir uma questão: no Juízo reflexionante é a imaginação que legisla o entendimento ou o contrário? ${ }^{4}$

Como vimos, o emaranhado de paradoxos da exposição simbólica kantiana parece nascer da concordância entre imaginação e entendimento, a qual, ao expor-se, deriva justamente em "[...] atributos estéticos [...] que vão ao lado dos lógicos e dão arrojo à imaginação para pensar mais [...]" (KANT, 1974, p. 346). Para Kant, conforme afirma Lebrun, é o Juízo-de-gosto que reconhece "[...] o feliz encontro entre a imaginação e o entendimento como a marca da condição suprema de todo conhecimento possível [...]" (LEBRUN, 2002b, p. 492).

Sendo assim, do acordo entre estas duas faculdades-da-mente - pois, ainda em Lebrun, agora em tom pessoal, "[...] a $3{ }^{\text {a }}$ Crítica tem o direito de se recolocar em uma fase onde, para mim, entendimento e imaginação ainda não estão cindidos [...]" (Idem, 2002a, p. 461) - perguntamos: é possível afirmar aqui que a imaginação é autônoma, ou seja, que ela sobrepuja o entendimento, dominando-o? Lemos o seguinte no §49:

[...] do ponto de vista estético, em contrapartida, ela [a imaginação] é livre, para, ainda além dessa concordância com o conceito, embora sem procurá-lo, fornecer ao entendimento matéria rica [...] indiretamente também para conhecimentos (KANT, 1974, p. 347-348).

De acordo com esse trecho, a imaginação tem, mesmo que livre de conceitos, uma função que, no Gênio, a impede de ser completamente livre. Todavia, da função indireta de fornecer matéria "para conhecimentos", poderíamos concluir então, ao revés, que a imaginação está condenada ao servilismo, enquanto fornecedora de "matéria rica" para o entendimento? Tampouco nos parece ser isso o que Kant aponta aqui.

\footnotetext{
${ }^{4}$ Problema, aliás, que já adiamos muito e que, em vários momentos de nossa exposição, passamos ao largo ou simplesmente o resvalamos. Primeiro, quando, na distinção do juízo reflexionante do juízo determinante, observamos que se tratava de uma relação paradoxal entre a linguagem simbólica e a linguagem lógica, ou antes, entre um acordo da imaginação com o entendimento; segundo, quando, na caracterização do juízo reflexionante como estético, sem nenhum interesse e universalmente-subjetivo, Kant atribuía ao Juízo-de-gosto um possível vínculo da imaginação ao entendimento; terceiro, quando, na cisão entre natureza e arte, o filósofo servia-se da exposição lógica e da exposição estética para distinguir a obra humana da obra animal, posteriormente reconciliando natureza e arte na bela-arte como se fosse natureza; quarto, quando, por fim, no estabelecimento da relação entre Gênio e gosto, notamos que nesta relação existia uma disposição "adequada e harmoniosa" entre imaginação e entendimento, ainda que não saibamos a proporção de cada uma destas faculdades no Juízo.
} 
Em verdade, se a imaginação em nenhum patamar da "pirâmide do conhecimento" aparece, nem por isso deixa de cooperar-lhe: ela tem um papel para "conhecimentos", apesar de não procurar o conceito e de não legislar a razão. Porém, como se trata de um "jogo rapidamente transitório da imaginação" (Ibidem, 1974, p. 348) que se unifica ao conceito no e por meio do artista (o qual apreende esse jogo produzindo a bela-arte, quer na literatura, quer nas artes plásticas ou cênicas), acaba que a imaginação funciona no anonimato, sem nomeações ou méritos reconhecidos.

Uma passagem presente em O Espírito e a Letra, de Rubens Rodrigues Torres Filho, obra que, embora tenha como análise a imaginação pura em Fichte, de modo conciso, claro e belo é capaz de sintetizar magistralmente o lugar não menos paradoxal no qual se encontra a imaginação em Kant e de instigar-nos para um exercício filosófico muito mais aprofundado do que o que acabamos oferecendo no presente artigo.

Mesmo na Crítica do Juízo, quando a questão do Juízo reflexionante leva, para além do esquematismo, à descoberta da universalidade de um "livre jogo" das faculdades, requerido, não mais unicamente para o conhecimento objetivo, mas para o "conhecimento em geral", e no qual a imaginação não está mais a serviço do entendimento nem da razão, nem por isso a faculdade-de-imaginar se torna legisladora: ela tem uma função, mas nunca chega a ter títulos (TORRES FILHO, 1975, p. 95).

Correspondência: Carlos Henrique dos Santos Fernandes. Universidade Federal de São Carlos - UFSCar, Rodovia Washington Luís, Km 235, s/n, Jardim Guanabara, CEP 13565-905, São Carlos, SP, Brasil. E-mail: carlos.fernandes.ufscar@hotmail.com

Conflito de interesses: Nenhum.

Todos os autores leram e aprovam a versão final submetida a revista Em curso 


\section{Bibliografia}

KANT, I. Crítica do juízo. 1. ed. Tradução de Rubens Rodrigues Torres Filho. São Paulo: Editora Abril Cultura. 1974. p. 335-363. (Coleção "Os Pensadores", v. 25).

KANT, I. Introdução à crítica do juízo: duas introduções à Crítica do Juízo. São Paulo: Editora Iluminuras, 1995, p. 93-129.

KANT, I. Crítica da Faculdade do Juízo. 2. ed. Tradução de Valerio Rohden e António Marques. São Paulo: Forense Universitária, 2005. p. 198-199.

LEBRUN, G. A finalidade sem fim e a ambiguidade do belo. In: Kant e o fim da metafísica. São Paulo: Martins Fontes, 2002a. p. 441-482.

LEBRUN, G. Os paradoxos da intersubjetividade. In: Martins Fontes, 2002b. p. 483-527.

LEBRUN, G. O gênio e a linguagem do imaginário. In: Martins Fontes, 2002c. p. 529-562.

LEBRUN, G. A imaginação sem imagens. In: . Kant e o fim da metafísica. São Paulo: Martins Fontes, 2002d. p. 563-596.

LEBRUN, G. A razão prática na Crítica do Juízo: sobre Kant. Tradução de Maria Regina Avelar Coelho da Rocha. São Paulo: Editora Iluminuras, 2010. p. 99-118.

NASCIMENTO, L. F. S. Intersubjetividade e senso comum em Kant. DoisPontos: estrutura, sistema, subjetividade. Curitiba, v. 5, n. 1, abr. 2008, p. 115-122.

PIMENTA, P. P. G. Kant e a estrutura orgânica da razão. Doispontos: estrutura, sistema, subjetividade. Curitiba, v. 5, n. 1, abr. 2008, p. 123-138.

TORRES FILHO, R. R. A Imaginação radical. O Espírito e a Letra: imaginação pura, em Fichte. São Paulo: Ática, 1975. Originalmente, tese de doutoramento apresentada à Universidade de São Paulo, em 1972, p. 95. cap. 2. 